\title{
Investigation of Morphology and Photocatalytic Activities of Electrospun Chicken Feather Keratin/PLA/TiO $/$ /Clay Nanofibers
}

\author{
Isarankura Na Ayutthaya Siriorn ${ }^{1,2 *}$, and Wootthikanokkhan Jatuphorn ${ }^{3,4}$ \\ ${ }^{1}$ Division of Aircraft Maintenance Engineering Technology, Department of Power Engineering Technology, College of Industrial \\ Technology, King Mongkut's University of Technology North Bangkok, Bangkok, Thailand. \\ ${ }^{2}$ Research Centre for Combustion Technology and Alternative Energy - CTAE, College of Industrial Technology, King Mongkut's \\ University of Technology North Bangkok, Bangkok, Thailand. \\ ${ }^{3}$ Division of Materials Technology, School of Energy, Environment and Materials, King Mongkut's University of Technology \\ Thonburi, Bangkok, Thailand; \\ ${ }^{4}$ Nanotec-KMUTT Center of Excellence on Hybrid Nanomaterials for Alternative Energy (HyNAE), School of Energy, Environment \\ and Materials, King Mongkut's University of Technology Thonburi, Bangkok, Thailand.
}

\begin{abstract}
This research has focused on the fabrication of electro spun-keratin base composite nanofiber, in order to develop the organic dye removal filters. The filters were prepared from a keratin-base material, which was extracted from chicken feathers. A biodegradable polymer including Poly (lactic acid) was blended into keratin to improve fibre process-ability. Titanium dioxide (anatase) and clay (Namontmorillonite) were mixed into the PLA/Keratin blended solution prior to fabrication into non-woven fibre using the electro-spinning process. The objective of this research was to study the effect of $\mathrm{TiO}_{2}$ and clay on the process-ability, the morphology, and the filter efficiency (methylene blue removal) of the fibres. SEM images showed the morphology of small PLA/Keratin/clay-base fibres. SEM-scan mapping EDX technique showed a good dispersion of keratin, clay and $\mathrm{TiO}_{2}$ along the fibres. XRD pattern also showed the existence of PLA, keratin and $\mathrm{TiO}_{2}$. But the peak of clay was not strong enough. However, the evidence of clay was clearly shown by SEM-EDX technique as reported above. The capability to remove organic dye (methylene blue) was investigated by using UV-Vis spectrophotometer technique. From all of our results, it can be concluded that PLA/Keratin/ $/ \mathrm{TiO}_{2} / \mathrm{clay}$ is an effective filter for the removal of organic dye from wastewater.
\end{abstract}

\section{Introduction}

Over 3,600 million tons per year of chicken feather waste have been found around the world [1]. Normally, chicken feather waste is either disposed of or used as fodder. However, it is still a major problem in each country, especially Thailand. Chicken feathers comprise of Keratin $91 \%$, Fat $1.3 \%$ and water $7.7 \%$. In order to use chicken feathers as a value-added product, extraction of keratin from the feathers is necessary [2].

Keratin is a kind of protein that has the biodegradable and the biocompatible properties, i.e. binds to cells easily and has various chemical reactive sites, e.g. carboxylic group, hydroxy group, amine group, aromatic group and thiol group. Thus, keratin has been used as framework for tissue engineering applications [3-5] and filters for the removal of heavy metals and some organic compounds. [6]. For filter applications, it can be prepared by using various techniques including self-assembly, phase separation, drawing, template synthesis and electrospinning technique [7]. The advantage of the electrospinning process is that it has more impact because it has a continuous process, which is possible to scale up [8]. Nevertheless, electrospinning technique by using a raw material that has low molecular weight, is very difficult. It is due to the low entanglement of molecules. Also, the molecular weight of keratin is very low, about $11-20 \mathrm{kDa}[3,4]$.
Generally, the process ability of low molecular weight proteins can be recovered by mixing with the long chain polymers, such as poly (ethylene oxide), poly (vinyl alcohol), and poly (lactic acid) [9-11]. The latter one is a suitable polymer for filter application due to its hydrophobic properties and good biodegradability which is environmentally friendly $[3,7]$. However, Keratin and poly (lactic acid) (PLA) are incompatible materials due to their different hydrophilic properties [12, 13]. To improve compatibility of these two materials, Montmorillonite (MMT), a kind of clay, is used as a compatibilizer between Keratin and PLA because MMT has high surface reactivity, high ion-exchange properties and a huge surface area, which interacted to Keratin and PLA [12, 14].

From results of our previous work, MMT was also used as a filler to improve viscosity and process-ability of electro-spinning. In addition, MMT also acts as a nucleating agent, increasing the crystallinity of Keratin, in view of the fact that the bonding between the hydrophilic octahedral surface of clay and the positive ion of amino groups of keratins. In addition, it also attributes to the interaction between the positive ion at the edge of clay and the negative ion at hydroxyl groups of poly (lactic acid) [12].

$\mathrm{TiO}_{2}$ is an effective material that can decompose the organic dye in waste water. However, $\mathrm{TiO}_{2}$ has a high 
agglomerate character and high hydrophilic properties, whereas PLA has hydrophobic character. Therefore, if $\mathrm{TiO}_{2}$ is blended into PLA matrix, it could be a problem for phase separation due to the big difference in hydrophilic properties. In order to improve the efficiency of filters that are used for organic removal from wastewater, it is of interest to investigate the potential of using MMT to increase $\mathrm{TiO}_{2}$ dispersion and the process-ability of keratin/PLA/TiO 2 blend.

From literature reviews, an investigation of the preparation and characterization of $\mathrm{PLA} / \mathrm{Keratin} / \mathrm{TiO}_{2}$ blend, which compatibilized with MMT, has not been reported. The purpose of this work is to study the effect of $\mathrm{TiO}_{2}$ and clay on the process-ability, the morphology, and the organic removal efficiency of the filter (under dark, $\mathrm{UV}$ and visible light illumination conditions) is of our interest.

\section{Experimental}

\subsection{Materials and chemicals}

Chicken feathers were received from the Better Foods Company Limited. PLA 2002D from NatureWorks LLC. Sodium montmorillonite (Cloisite $\mathrm{Na}^{+}$) was provided from Southern Clay Products (Gonzales, TX). Titanium dioxide (Anatase grade) and formic acid (98\%, Analysis grade) were supplied from Carlo Erba Reagents (France) and Merck Co., Ltd., respectively. Chloroform (analysis grade) and acetone (laboratory grade) were provided from RCI Labscan, and Siam Beta Group Co., Ltd., respectively.

\subsection{Extraction of keratin}

The Keratin was extracted from chicken feathers using the sulphitolysis method [7] as briefly described in the following. $7 \mathrm{~g}$ of cleaned and short feathers were submerged in $250 \mathrm{~mL}$ of the aqueous solution comprising of $8 \mathrm{M}$ of urea, $0.2 \mathrm{M}$ of sodium metabisulphite, $4.2 \mathrm{~g}$ of sodium dodecyl sulphate, then adjusted the $\mathrm{pH}$ to be 6.5 . The aqueous solution was stirred at $65^{\circ} \mathrm{C}$ for $5 \mathrm{hrs}$ then filtered by the mesh of nylon (150 and $50 \mu \mathrm{m}$ respectively). The aqueous solution filtrate was dialyzed in a dialysis tube (MWCO $6-8 \mathrm{kDa}$ ) by distilled water for $72 \mathrm{~h}$. The distilled water was changed 3 times a day. Subsequently, the aqueous solution was evaporated by using a rotary evaporator (Heidolph, Laborota4003 Control) at $40^{\circ} \mathrm{C}$ and $45 \mathrm{mBar}$. Lastly, the intense keratin was freeze-dried until it had constant weight.

\subsection{Preparation of keratin/PLA base nanofibers}

\subsubsection{Poly (lactic acid) solution preparation}

$1 \mathrm{~g}$ of poly (lactic acid) was stirred in $9 \mathrm{~mL}$ of chloroform/acetone $(70 / 30 \mathrm{v} / \mathrm{v})$ at $70^{\circ} \mathrm{C}$ for $12 \mathrm{~h}$.

\subsubsection{Keratin base solution preparation}

Keratin solution: $1 \mathrm{~g}$ of keratin was stirred in $9 \mathrm{~mL}$ of formic acid at room temperature for $12 \mathrm{~h}$. Keratin and inorganic compounds ( clay or $\mathrm{TiO}_{2}$ or clay/ $\mathrm{TiO}_{2}$ ) solutions: Clay or $\mathrm{TiO}_{2}$ or clay/ $\mathrm{TiO}_{2}(\%$ wt. from Table 1) were added in formic acid and they were sonicated for 2 h. Consequently, keratin was added into organic formic and they were stirred for $24 \mathrm{~h}$.

\subsubsection{PLA/Keratin base solution preparation}

PLA/Keratin base solutions: PLA solution and keratin base solutions (with and without clay or $\mathrm{TiO}_{2}$ )) were blended by stirred for $24 \mathrm{~h}$.

\subsubsection{PLA/Keratin base nanofiber preparation}

Keratin/PLA nanofibers (with and without clay and $\mathrm{TiO}_{2}$ ) were fabricated using the electrospinning set (comprised of Gamma high voltage power supply (ES30P) and Syringe pump (NE-300)). The voltage, distance between a needle tip and collector and feed rate were $19 \mathrm{kV}, 15 \mathrm{~cm}$ and $5 \mu \mathrm{L} \mathrm{min}{ }^{-1}$, respectively. In this research, the formula of keratin/PLA base nanofibers are in Table 1 .

Table 1. The sample names and composition.

\begin{tabular}{|c|c|c|c|c|}
\hline Sample names & $\begin{array}{c}\text { PLA } \\
\text { (\% wt) }\end{array}$ & $\begin{array}{c}\text { Keratin } \\
\text { (\% wt) }\end{array}$ & $\begin{array}{c}\mathrm{TiO}_{2} \\
\text { (\% wt) }\end{array}$ & $\begin{array}{c}\text { Clay } \\
\text { (pph) }\end{array}$ \\
\hline $\mathrm{PLA} / \mathrm{TiO}_{2}$ & 66.66 & - & 33.33 & - \\
\hline PLA/Keratin & 50 & 50 & - & - \\
\hline PLA/Keratin-Clay & 50 & 50 & - & 2 \\
\hline PLA/Keratin/ $/ \mathrm{TiO}_{2}$ & 33.33 & 33.33 & 33.33 & - \\
\hline PLA/Keratin/TiO ${ }_{2}$-Clay & 33.33 & 33.33 & 33.33 & 2 \\
\hline
\end{tabular}

\subsection{Characterizations}

\subsubsection{Morphology of the nanofibers}

The nanofiber morphology characterization was observed using a scanning electron microscopy (LEO $1450 \mathrm{VP}$ ) equipped with SE detector with applied voltage of $15 \mathrm{kV}$. The element of nanofibers was from scan mapping by using the EDS technique. The average diameter of the nanofiber was measured by using the image- $J$ analysis software.

\subsubsection{Crystallinity of the nanofibers}

The crystallinity of the nanofibers was investigated using $\mathrm{X}$-ray diffraction technique (XRD), Bruker AXS Model: D8DISCOVER $40 \mathrm{kV}, 40 \mathrm{~mA}$.

\subsubsection{Absorbance of the electro spun nanofibers}

The absorbance of electrospun nanofibers was investigated by using UV-vis spectrometry (Shimadzu UV-vis 3100 ). The samples were scanned by using the wavelength of 200-800 $\mathrm{nm}$. 


\subsubsection{Removal capabilities of Methylene blue}

The removal abilities of methylene blue (MB) of the nanofiber filters were observed by note of concentration of $\mathrm{MB}$ in the aqueous solution under visible light illumination, ultraviolet (UV) and in the dark. $0.05 \mathrm{~g}$ of the filters were suspended into $50 \mathrm{~mL}$ of methylene blue solution $\left(5 \times 10^{-6} \mathrm{M}\right)$ prior to sonication for $30 \mathrm{~min}$. The suspension was kept stirring in each condition for another $30 \mathrm{~min}$ at room temperature.

For the observation of $\mathrm{MB}$ removal (in the dark, visible and UV condition), $10 \mathrm{~mL}$ of the suspension were taken every $30 \mathrm{~min}$. The sampling suspension was centrifuged, prior to measure the absorbance of MB peak at $664 \mathrm{~nm}$ by using a UV-Vis spectrometer (Genesys 10s). After the measurement, the sampling solutions were refilled in the reaction flask again. The measurement step was continued until $6 \mathrm{~h}$ was reached. MB removal was evaluated in term of $\mathrm{C} / \mathrm{C}_{0}$, where $\mathrm{C}_{0}$ is the initial concentration of $\mathrm{MB}$ and $\mathrm{C}$ is the concentration at a given time.

\section{Results and discussion}

\section{1. Morphology, $\mathrm{TiO}_{2}$ and keratin distribution inside PLA and PLA/keratin base nanofibers}

Fig. 1a and $1 \mathrm{~b}$ showed the surface morphology and $\mathrm{TiO}_{2}$ particles dispersion inside $\mathrm{PLA} / \mathrm{TiO}_{2}$ fibres. The agglomerated particles of $\mathrm{TiO}_{2}$ inside the fibres, and the large diameter of the fibres were found. The large diameter was due to the very low conductivity and high viscosity of $\mathrm{PLA} / \mathrm{TiO}_{2}$ composite solution, as described in previous work $[7,15]$. However, poor interfacial phase interaction between $\mathrm{TiO}_{2}$ and PLA, and overloaded of $\mathrm{TiO}_{2}$ particles into the PLA fibres, resulted in poor dispersion and agglomeration of $\mathrm{TiO}_{2}$ particles inside the fibres [16].

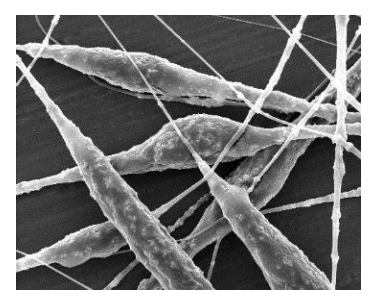

(a)

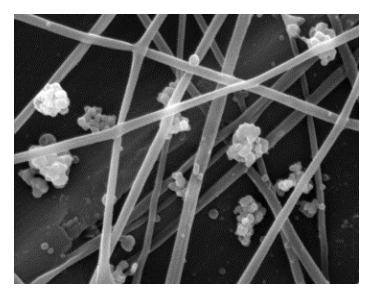

(c)

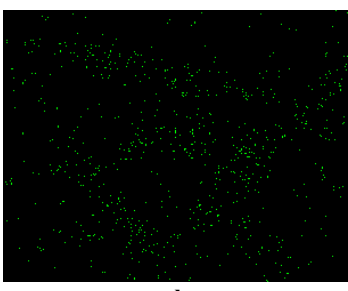

(b)

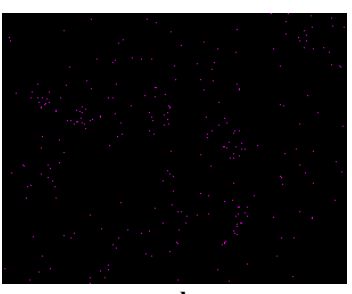

(d)
Fig. 1. SEM images of electrospun fibres (a and c) and their composites (b and d) via scan-mapping EDX technique: $\mathrm{PLA} / \mathrm{TiO}_{2}$ ( $\mathrm{a}$ and $b$ ), and PLA/keratin/ $/ \mathrm{TiO}_{2}$ (c and d).

Morphology of PLA/Keratin/ $\mathrm{TiO}_{2}$ was shown in Fig. 1c. It showed the improvement of $\mathrm{TiO}_{2}$ dispersion inside PLA/Keratin phase because $\mathrm{TiO}_{2}$ was mixed into keratin solution (keratin and $\mathrm{TiO}_{2}$ were dissolved in formic acid) before blended with PLA solution. Therefore, $\mathrm{TiO}_{2}$ surfaces were modified by organo- acid (keratin-formic acid), which improved the dispersion of $\mathrm{TiO}_{2}$ inside Keratin phase.

However, from previous researches, keratin and PLA were not a miscible blend. The morphology of keratin and PLA are the core-shell structure, which has keratin as a shell section. It could be concluded that the $\mathrm{TiO}_{2}$ particles were dispersed along keratin shell phase [12, 16-20] . However, some agglomerated $\mathrm{TiO}_{2}$ particles were still appeared along fibre because of the high content of $\mathrm{TiO}_{2}$ inside that fibre, as compared to previous reported [21, 22].

\subsection{Effect of Clay on $\mathrm{TiO}_{2}$ dispersion and PLA keratin/ $/ \mathrm{TiO}_{2}$ electro spun nanofibers}

From our previous research, clay was found to be a factor that improved the process ability of PLA/ keratin electrospun nanofiber. Clay acted as a coupling agent between PLA and keratin phases [12]. For this research, as expected, without clay, the number of agglomerated $\mathrm{TiO}_{2}$ were revealed, as shows in Fig 2a. Whereas, clay acted as a disperser of $\mathrm{TiO}_{2}$ particles inside PLA/keratin fibres, as shows in Fig. 2b. This could be due to $\mathrm{TiO}_{2}$ interacted with clay via ionic interaction $[12,23]$.

To test for the ionic interaction as mentioned above, Keratin/ $\mathrm{TiO}_{2}$ solution was blended into PLA solution during the solution preparation step. Keratin was dissolved in formic acid, then $\mathrm{TiO}_{2}$ was mixed into the keratin solution. Therefore, Keratin and $\mathrm{TiO}_{2}$ were surrounded by acidic condition, which consequently turned Keratin and $\mathrm{TiO}_{2}$ into Keratin- $\mathrm{NH}^{3+}$ and $\mathrm{TiOH}^{2+}$, respectively $[12,23]$.

These positive matters could be directly interacted to anionic surfaces of clays which make them disperse along the Keratin-shell layer of fibres [12]. Good dispersion of Keratin ( N), $\mathrm{TiO}_{2}$ ( $\mathrm{Ti}$ ) and clay ( $\mathrm{Si}$ ) along the $\mathrm{PLA} / \mathrm{Keratin} / \mathrm{TiO}_{2}$ - clay nanofiber by using SEM-scan mapping EDX technique were shown in Fig.3.

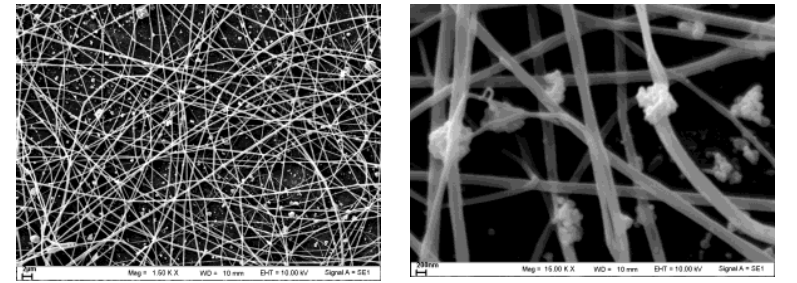

(a) PLA/Keratin/ $/ \mathrm{TiO}_{2}$

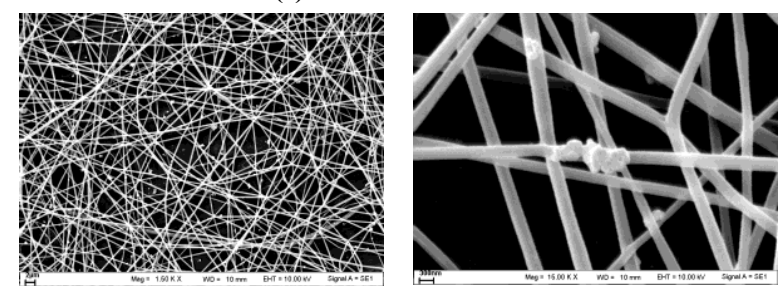

(b) PLA/KeratinTiO $\mathrm{TiO}_{2}$ - Clay $2 \mathrm{pph}$

Fig. 2. SEM images of electrospinning fibers: PLA/Keratin/ $\mathrm{TiO}_{2}$ (a), and PLA/keratin/TiO 2 -clay (b). 


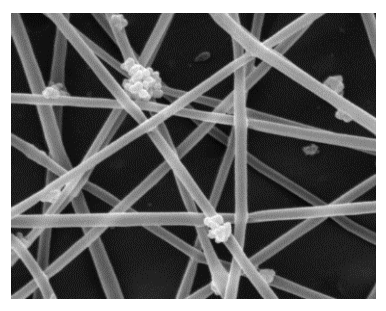

(a)

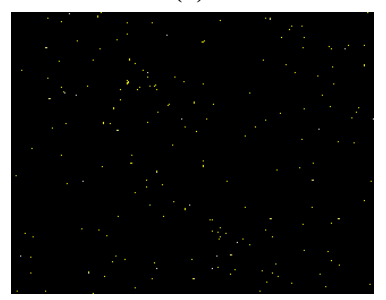

(c)

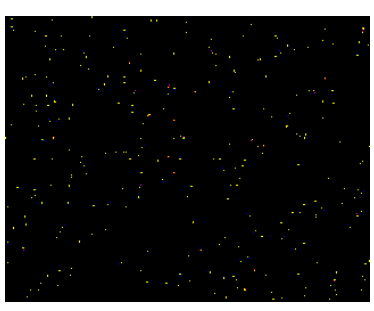

(b)

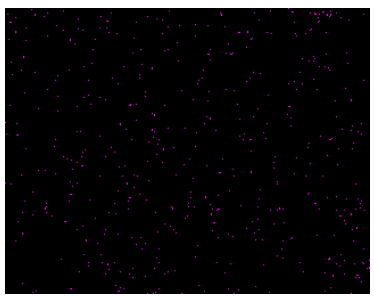

(d)
Fig. 3. SEM images of PLA/keratin/ $/ \mathrm{TiO}_{2}$-clay fibres (a), SEM-scan mapping EDX of Keratin (b), $\mathrm{TiO}_{2}(\mathrm{c})$ and Clay (Si) (d).

\subsection{Crystal structure of nanofibers}

Fig. 4 shows XRD patterns of neat- $\mathrm{TiO}_{2}$, neat-clay, neatkeratin, PLA fibre mat, and the blended fibres of these raw materials. XRD pattern peaks of PLA/Keratin/ $/ \mathrm{TiO}_{2}$, with and without clay, retained representing PLA hump and $\mathrm{TiO}_{2}$ peak at $18.0^{\circ}$ and $25.28^{\circ}$ respectively [21]. However, clay peak pattern of electrospun PLA/ Keratin/ $\mathrm{TiO}_{2}$ / clay fibres was not showed up significantly. It was due to it having too low a concentration of clay ( $2 \mathrm{pph}$ ) inside the fibres. Clay retained in the fibre was showed by SEM scan-mapping EDX technique (Fig.3-d), as discussed above.

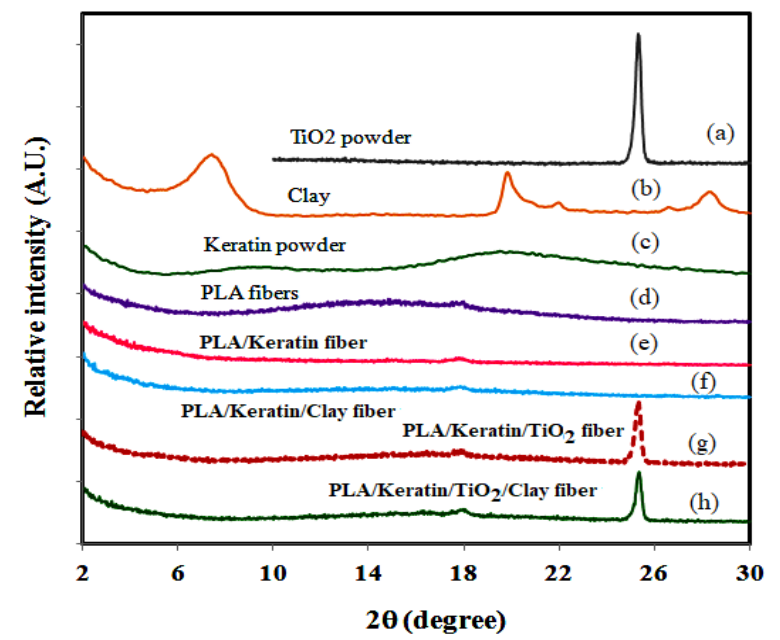

Fig. 4. XRD patterns of $\mathrm{TiO}_{2}$ powder (a), clay (b), keratin powder (c), PLA fibre (d), PLA/keratin fibre (e), PLA/keratin/clay fibre (f), $\mathrm{PLA} /$ keratin/ $/ \mathrm{TiO}_{2}$ (g), and PLA/keratin/ $/ \mathrm{TiO}_{2} /$ clay fibre (h).

\subsection{UV-Vis absorption of filters}

For comparison of different types of composites, the spectra of fibres were observed by UV-Vis spectrometry and the results showed that characteristic absorbance peak of PLA at $250 \mathrm{~nm}$ can be observed. This suggests that the PLA can absorb the light in UVC region.

The peaks representing Keratin and $\mathrm{TiO}_{2}$ were $290 \mathrm{~nm}$ and $370 \mathrm{~nm}$, respectively. The results showed that Keratin can absorb light in the range of UVC- UVB regions. Meanwhile, by adding $\mathrm{TiO}_{2}$, absorbance of PLA/Keratin shifted to the longer wavelength (from 250 to $370 \mathrm{~nm}$ ). This was attributed to the presence of $\mathrm{TiO}_{2}$, which is capable of absorbing the light close to visible region (UVB to UVA) (Fig.5). By adding clay, the representing absorbance peak of PLA/Keratin and PLA/Keratin/ $\mathrm{TiO}_{2}$ showed the strong peak of clay at 215 and $255 \mathrm{~nm}$. Clay was a good absorbent at UVC-UVB region [24-25].

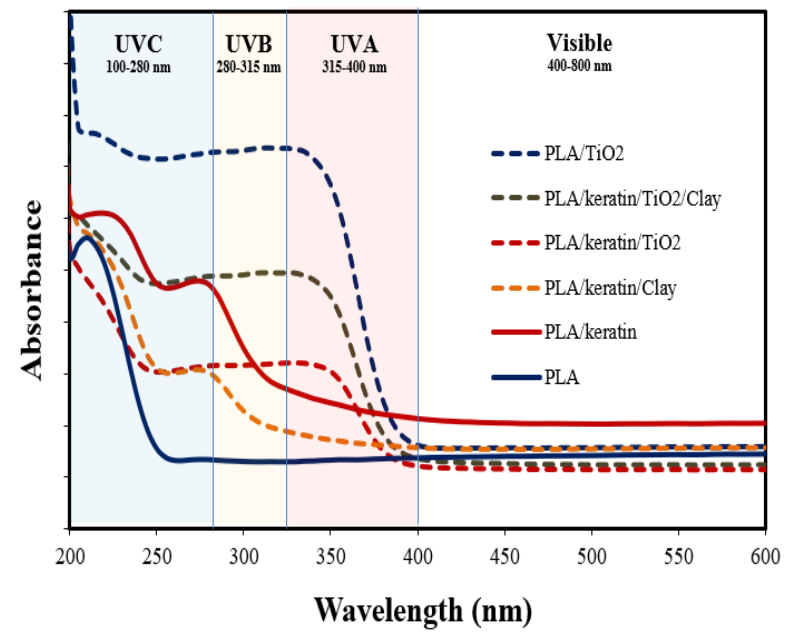

Fig. 5. UV-Vis spectra of electrospun PLA, PLA/Keratin, PLA/ $\mathrm{TiO}_{2}$, PLA/Keratin/TiO 2 , PLA/Keratin/clay and PLA/Keratin/ $\mathrm{TiO}_{2} /$ clay nanofibers.

\subsection{Photocatalytic activity of filters}

In this work, methylene blue (MB) removal capabilities was investigated. The absorption of methylene blue in the dark of various composite fibre was revealed in Fig.6. As expected, PLA and $\mathrm{TiO}_{2}$ have low efficiency to remove methylene blue from the media solution. Whereas, Keratin acted as methylene blue adsorption material, via ion-exchange between methylene blue $\left(\mathrm{R}-\mathrm{N}^{+}\right)$and keratin $\left(\mathrm{R}-\mathrm{COO}^{-}\right)$. Furthermore, clay acted as a good adsorption material, which decreased concentration of methylene blue significantly. It was because the negative charge at clay surface interacted to the positive charge of methylene blue. However, if clay and $\mathrm{TiO}_{2}$ were mixed together, $\mathrm{TiO}_{2}\left(\mathrm{TiO}^{4+}\right)$ can be interacted directly to surface negative charge of clay as well. Accordingly, it affected the MB removal efficiency of clay, as showed in Fig. 6.

In this part, it was also noteworthy that degradation of MB in the presence of the neat clay under UV irradiation and visible light illumination as shown in Fig. 7 and 8 . This was similar from that was carried out in the dark (Fig. 6 ), which concentration of $\mathrm{MB}$ was depleted due to absorption. 


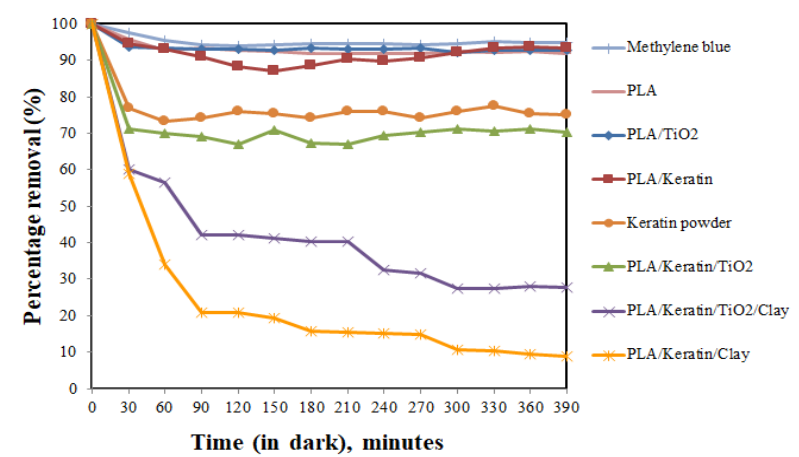

Fig. 6. Methylene blue absorption - in the dark condition

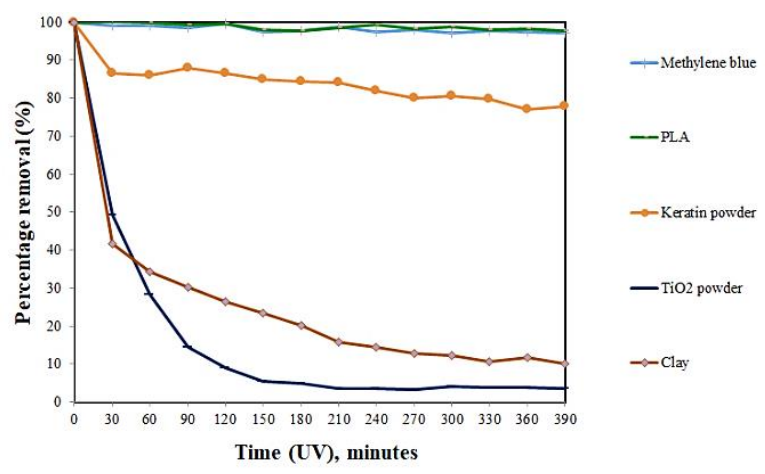

Fig. 7. Methylene blue absorption of neat-PLA fibre mat, keratin powder, $\mathrm{TiO}_{2}$ powder and clay under UV condition.

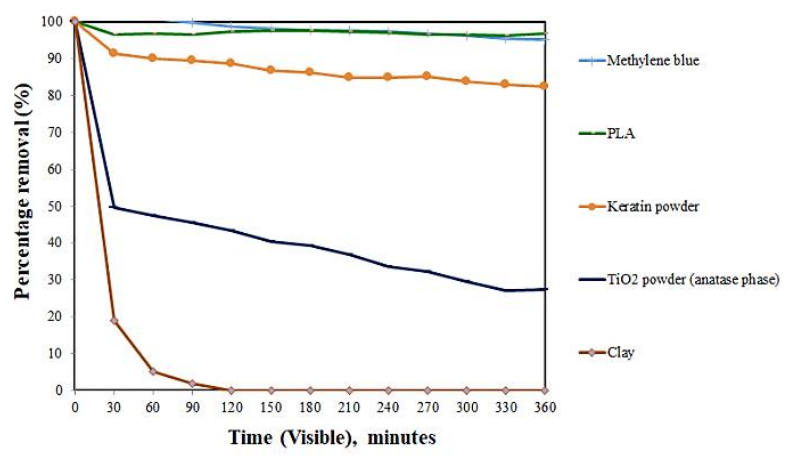

Fig. 8. Methylene blue absorption of neat-PLA fibre mat, keratin powder, $\mathrm{TiO}_{2}$ powder and clay under visible condition.

Fig. 9 showed the methylene blue removal by various types of powder and fibres, under UV irradiation. The results presented that photocatalytic activity under UV light of electrospun PLA/ $/ \mathrm{TiO}_{2}$ was the best, (approaching that of the neat $\mathrm{TiO}_{2}$ anatase powder). However, $\mathrm{PLA} / \mathrm{Keratin} / \mathrm{TiO}_{2}$ was more stable and its photocatalytic activity was also demonstrated. On the other hand, $\mathrm{PLA} / \mathrm{TiO}_{2}$ nanofiber also decomposed very well after UV irradiation because $\mathrm{TiO}_{2}$ particles breaked out of the agglomerated fibre. Thus, methylene blue was trapped by enormous surface of $\mathrm{TiO}_{2}$ particles that dispersed in the solution. Furthermore, by adding clay, it was found that degradation of MB was enhanced. This was in a good agreement with the fact that MB was also degraded under UV illumination in the presence of clay.
The methylene blue removal by various types of composite fibres under visible light illumination was shown in Fig. 10. The results showed that $\mathrm{TiO}_{2}$, clay and Keratin were not active obviously, under visible condition. Also, clay still removed methylene blue via mechanism of adsorption as well.

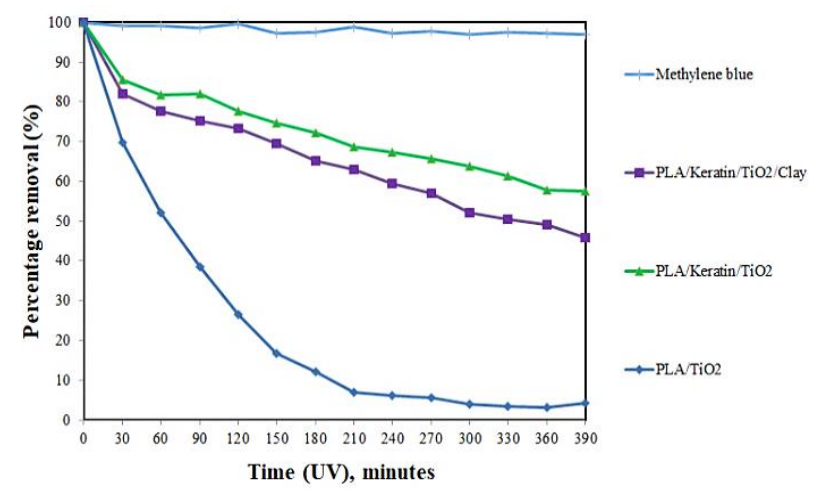

Fig. 9. Methylene blue absorption of composite fibres under UV condition.

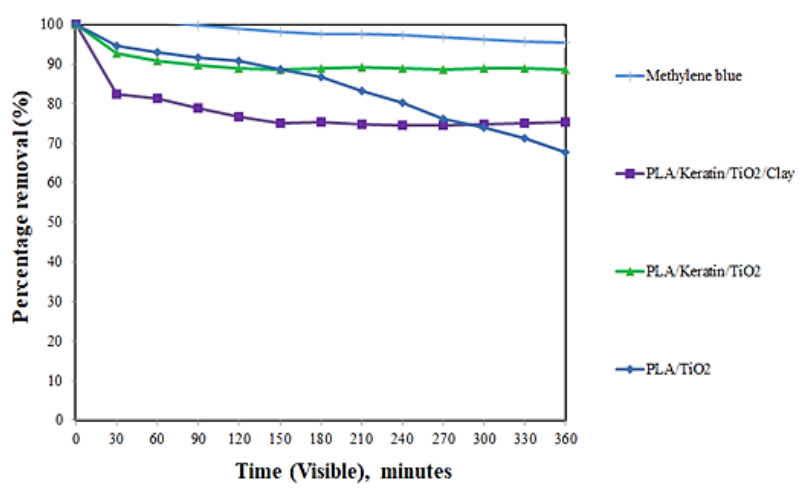

Fig. 10. Methylene blue absorption of composite fibres under visible condition.

\section{Conclusion}

Keratin-base materials can be fabricated into electrospun fibres. Without Keratin, $\mathrm{TiO}_{2}$ particles cannot disperse along PLA fibres easily. In addition, clay act as a disperser of $\mathrm{TiO}_{2}$ particles along the PLA/keratin fibres as well. Furthermore, methylene blue can be adsorbed and removed by Keratin and clay, in every condition (in dark, UV and visible). Especially, clay, which acted as a great adsorption material, decreased concentration of methylene blue significantly. As expected, under UV conditions, the materials that acted best as a photocatalytic dye degradation was $\mathrm{TiO}_{2}$. Nevertheless, focusing on the fiber filter, the highest efficient filter that fabricated from this research was PLA $/ \mathrm{Keratin} / \mathrm{TiO}_{2} / \mathrm{clay}$, which can remove organic dye by adsorption and photocatalytic dye degradation mechanism.

This research was funded by College of Industrial Technology, King Mongkut's University of Technology North Bangkok (Grant No. Res-CIT0226/2018). 


\section{References}

1. S. Barbut, CRC Press LLC (Boca Raton, Florida, 2002)

2. S.K. Chinta, S.M. Landage, Y. Krati, IJIRSET. 2 (2013)

3. J. Yuan, J. Shen, I.-K. Kang, Polym Int. 57 (2008)

4. M. Zoccola, A. Aluigi, C. Vineis, C. Tonin, F. Ferrero, M.G. Piacentino, Biomacromolecules. 2819 (2008)

5. A. Aluigi, A. Corbellini, F. Rombaldoni, M. Zoccola, M. Canetti, Int. J. Biol. Macromol. 30 (2013)

6. A. Ghosh, S.R. Collie, Defence Sci J. 209 (2014)

7. S. Isarankura Na Ayutthaya, S. Tanpichai, J. Wootthikanokkhan, J Polym Environ. 506 (2015)

8. S. Ramakrishna, K. Fujihara, W.-E. Teo, T.-C. Lim, Z Ma, World Scientific (Singapore, 2005)

9. K. Katoh, M. Shibayama, T. Tanabe, K. Yamauchi, J Appl Polym Sci. 756 (2004)

10. M. Zoccola, A. Montarsolo, A. Aluigi, A. Varesano, C. Vineis, C. Tonin, E-Polymers. 1204 (2007)

11. A. Aluigi, C. Tonetti, C. Vineis, C. Tonin, G. Mazzuchetti, Eur Polym J. 1756 (2011)

12. S. Isarankura Na Ayutthaya, S. Tanpichai, W. Sangkhun, J. Wootthikanokkhan, Int J Biol Macromol. 585 (2016)

13. J. Li, Y. Li, L. Li, A.F.T. Mak, F. Ko, L. Qin, Polym Degrad Stab. 1800 (2009)
14. Y. Kishimoto, F. Ito, H. Usami, E. Togawa, M. Tsukada, H. Morikawa, S. Yamanaka, Int J Biol Macromol. 124 (2013)

15. Z. Wang, Z. Pan, J. Wang, R. Zhao, J Nanomater. 6272983 (2016)

16. D.V. Cong, N.T.T. Trang, N.V. Giang, T.H. Trung, N.T. Chinh, M.D. Huynh, T. Hoang, Polym Korea. 355 (2016)

17. N. Fukuda and H. Tsuji, J Appl Polym Sci. 190 (2005)

18. N. Nakayama and T. Hayashi, Polym Degrad Stab. 1255 (2007)

19. X. Lu, X. Lv, Z. Sun, and Y. Zheng, Eur Polym J. 2476 (2008)

20. Y. B. Luo, X. L. Wang, and Y. Z. Wang, Polym Degrad Stab. 721 (2012)

21. K.K. Gupta, P.P. Misha, P. Srivastava, M. Gangwar, G. Nath, P. Maiti, Appl Surf Sci. 375 (2013)

22. B. Nim, P. Sreearunothai, P. Opaprakasit, Appl Sci Eng Prog. 52 (2019)

23. A. Ajmal, I. Majeed, R.N. Malik, H. Idriss, M.A. Nadeem, RSC Adv. 37003 (2014)

24. G. Zehetmeyer, J.M. Scheibel, R.M.D. Soares, D.E. Weibel, M.A.S. Oviedo, R.V.B. Oliveira, Polym Bull. 2181 (2013)

25. J. Alin, M. Rubino, R. Auras, Appl Spectrosc. 671 (2015) 